\title{
Nanoparticle Technology of Dodecenol as Active Components in Cryptotermes Cynocephalus Control System
}

\section{Niken Subekti ${ }^{*}$, Ro'iyyatul Mar'ah ${ }^{1}$, Afrin Nur Aisyah ${ }^{1}$, Dina Fika Nada ${ }^{2}$ and Meidina Rahmawati $^{2}$}

${ }^{1}$ Biology Department, Universitas Negeri Semarang, Indonesia

${ }^{2}$ Chemistry Department, Universitas Negeri Semarang, Indonesia

\begin{abstract}
Cryptotermes cynocephalus is one of the Kalotermitidae species. In Indonesia, this species is known as wood-destroying pest. Damages incurred economic losses up to billions of rupiah per year. One of the technologies that can be used for controlling is nanotechnology of dodecenol pheromones. This study aims to analyze the effectiveness of nanoparticle pheromone dodecenol from Body Extract (BE) and Sternal Gland Extract (SGE) for controlling Cryptotermes cynocephalus through termite feeding preference and analysis of chemical components of both. Both extracts were analyzed using GC-MS then tested bios assay $Y$ to compare its effect on feeding behavior of termites. BE was then used as a main material to produce nanoparticle gel. The food-preference test was conducted using Petri dish assay and endurance test based on Indonesian National Standard 2006. Petridis assay and endurance test in this research used 6 treatment of dodecenol nanoparticle concentration $(0 \%, 5 \%, 10 \%, 15 \%$, $20 \%$, and $25 \%$ ) and 3 repetitions. The GC-MS chromatogram results show that in the termite extract there are dodecenol compounds. Bioassay $Y$ test showed that there was a difference between $B E$ and SGE effect on termite adaptation and termite $(P<0.05)$. The bioassay choice test of $Y$ shows that there is a difference in the effect of BE with SGE on the behavior of termites. BE is more influential than SGE with a significance level of $5 \%$. Petridis assay shows that nanoparticle $10 \%$ maximally increases termite preference to pine wood sample indicated by mass loss $13.856 \%$.
\end{abstract}

\section{Keywords}

Technology, Nanoparticle, Dodecenol, Drywood-termites

\section{Introduction}

In Indonesia drywood termite or Cryptotermes cynocephalus has been recorded as termites that are economically very harmful. Economically, more than billion rupiah loses per year [1,2]. The losses which is caused by $C$. cynocephalus lead people al- ways look for to control the termite growth [3].

The control of dry wood termites carried out in Indonesia generally uses termiticide. The results showed that wood preservation using boric acid is able to kill approximately $55.67 \%$ dry wood C. cynocephalu [4]. However, termiticides it is not environ-

*Corresponding author: Niken Subekti, Biology Department, Universitas Negeri Semarang, Indonesia, Tel: +62-024-8508033

Accepted: September 12, 2019; Published: September 14, 2019

Copyright: (C) 2019 Subekti N, et al. This is an open-access article distributed under the terms of the Creative Commons Attribution License, which permits unrestricted use, distribution, and reproduction in any medium, provided the original author and source are credited.

Subekti et al. Int J Nanoparticles Nanotech 2019, 5:031 
mentally friendly and likely extinguish non-target organisms. Besides that, the termiticide product, which is also widely used today is diflubenzuron and hexaflumuron formulated in bait form of. These compositions are more environmentally friendly, but the price is relatively very expensive, so the user community is very rare [5].

Dodecenol pheromones is environmentally friendly termiticide, due to relatively cheap, effective and high specify but little bit slowly in $C$. cynocephalus controlling. One of the efforts to improve dodecenol gel performance is applying nanoparticles technology. Carrier matrix materials used in nanoparticle technology is nanometer size chitosan. It aims to cut the duration of pheromone penetration and improve it works.

Chitosan in the form of nanoparticles was chosen because it has biocompatible, biodegradable, low toxicity and mucoadhesive properties [6]. Because of that, the study aims to analyze the effectiveness of nanoparticle of dodecenol feromone body extract and sternal gland extract in controlling $C$. cynocephalus through termite feeding preference and analysis of chemical components of both extracts. This research was provided beneficial value in the development of wood production technology in termite control using feeding techniques.

\section{Method}

This research had been done in Termite Biology Laboratory, Mathematics and Science Faculty, Universitas Negeri Semarang for preparing sample, making dodecenol, bioassay $Y$ and petridish assay for about 5 months. Method used in this study was experimental design.

\section{Termite preparation}

C. cynocephalus was obtained from termite farms in Entomology Laboratory Faculty of Chemical Product of Forest, Institute Pertanian Bogor (Bogor, Indonesia). All termites used in this study were adult workers/pseudergate termites 6-months-old. Termites were then adapted to the environment Laboratory of Termite Biology, Universitas Negeri Semarang (Semarang, Indonesia) at $28^{\circ} \mathrm{C}$ and humidity $68 \%-70 \%$.

\section{Dodecenol pheromone production}

The preparation of dodecenol extract sample was performed by liquid phase extraction method made from the whole body of the termites (Body Extract/BE) and the Stern Gland Extract (SGE). BE was produced by extracting 2000 adult individuals of pseudergate using $20 \mathrm{ml}$ of hexane at $4{ }^{\circ} \mathrm{C}$ for 12 hours, shaked slowly without destroy termites body. While SGE was produced by cutting the sternal glands under a stereo microscope using micro scissor and forceps. The severed sternal glands were then extracted using hexane as a solvent (with the composition is $4 \mathrm{ml}$ hexane for 1000 gland) at 4 ${ }^{\circ} \mathrm{C}$ for 12 hours. Both extracts can be used directly or stored at $-15{ }^{\circ} \mathrm{C}$ until the next analysis process [7].

\section{GC-MS analysis}

The entire body glands and the sternal glands were analyzed using gas chromatography followed by mass spectroscopy to find out the fragmentation of the dominant compound in it. Analysis GC-MS Analysis was conducted by applied Gas Chromatograph system 6890N (Agilent Technologies, Inc) combined with 5975 inert XL mass selective detector (Agilent Technologies, Inc). Electron Impact (EI) mass spectra was settled in the amount of electron energy is $70 \mathrm{eV}$, using an HP-5MS capillary column (Agilent Technologies Inc, $0.25 \mathrm{~mm}$ in diameter $\times 30 \mathrm{~m}$, and $0.25 \mu \mathrm{m}$ film thickness). Analytic column that was used is capillary fused silica. Helium $(\mathrm{He})$ was used as gas carrier with flow speed up to $37 \mathrm{~cm} / \mathrm{s}$. The samples in $\mathrm{GC}$ were settle in the temperature $40{ }^{\circ} \mathrm{C}$ to $220^{\circ} \mathrm{C}$ in $3^{\circ} \mathrm{C} / \mathrm{min}$. El mass spectra was collected from scanning the flow of electron's energy when the electron energy up to $70 \mathrm{eV}$, the scanning was conducted through wide gaps 25 to 300 a.m.u in $0.8 \mathrm{~s}$.

\section{Dodecenol Y bioassay}

Bioassay has done under standard conditions with a relative humidity of $\pm 70 \%$ and a room temperature at $28{ }^{\circ} \mathrm{C}$. The two extracts $\mathrm{BE}$ and SGE that had been produced (dodecenol) were tested using $\mathrm{Y}$ bioassay on Whatmann $\mathrm{N}^{\circ} 1$ disc paper (15 $\mathrm{cm}$ diameter), with an intermediate angle of $120^{\circ}$. In $Y(3 \mathrm{~cm})$ and one $Y(7 \mathrm{~cm})$ branch, artificial trail (BE and SGE) were drawn using a micro liter syringe in which there is $1 \mu$ extract per $1 \mathrm{~cm}$ marker. Other extracts or pure solvents (hexane) as controls, are placed in the same conditions on the basis of $Y$ and other $Y$ branches. Then a termite was placed in a small $55 \mathrm{~mm}$ diameter bottle at the base of $Y$, and the distance traveled by the termites is measured. 
The time spent between introducing termites to bottles and bottle relics by termites was also measured to determine the role of the marker in determining the behavior of termites [7].

$B E$ and SGE were tested to 30 replicates $(n=30)$ and each repetition used new termites and filter papers to prevent the effect of previous behavioral conditioning. The activity threshold for both extracts was determined as the minimum concentration that induces termites to travel an average distance of more than $3 \mathrm{~cm}$. While the maximum response was $10 \mathrm{~cm}[7,8]$.

\section{Dodecenol nanoparticle preparation}

Preparation of nanoparticle was done by dissolving 3 grams of chitosan in $100 \mathrm{~mL}$ glacial acetic acid 1\% then homogenized at $2000 \mathrm{rpm}$ for 2 hours. The homogeneous mixture was then added with $20 \mu \mathrm{L}$ tween $800.1 \%$ and homogenized again at $1000 \mathrm{rpm}$ at $25^{\circ} \mathrm{C}$ for $15 \mathrm{~min}$. Furthermore, 200 $\mathrm{ml}$ of TPP $0.1 \%$ and $2 \mathrm{ml} \mathrm{BE}$ added. This mixture was then homogenized at a rate of $1000 \mathrm{rpm}$ for 1 hour and formed nanoparticles $[9,10]$.

\section{Scanning Electron Microscopy (SEM) and Par- ticle Size Analyzer (PSA)}

Firstly, nanoparticle formed was frozen at -25 ${ }^{\circ} \mathrm{C}$ and then analyzed morphologically using SEM (Phenom pro $X$ Desktop SEM) at 1500× magnification. The droplet size of the nanoparticle was determined by photon correlation spectroscopy which analyzes the fluctuations in light scattering due to Brownian motion of the particles using PSA (Horiba LA-690 Particle Size Analyzer).

\section{Petridis assay}

Ten pseudergate $C$. cynocephalus were placed separately into $60 \times 15 \mathrm{~mm}$ Petridish which there was filled with $15 \mathrm{~mm}$ cut papers. In the control group, the papers was moistened using $1 \mathrm{~mL}$ of distilled water, other groups separately were filled with paper, which was moistened using $1 \mathrm{~mL}$ of nanoparticle at 6 different concentrations $(0 \%, 5 \%$, $10 \%, 15 \%, 20 \%$, and $25 \%$ ) and each test was performed 3 repetitions. All tests were then stored randomly in a sealed container for 4 days and the mortality was observed for each day [11].

\section{Result and Discussion}

\section{GC-MS analysis}

Dodecenol is specific chemical compound produced by dry wood termites, Kalotermitidae family. Dodecenol have a roll as trail following pheromone produced by pseudergates's sternal gland. Because of that, dodecenol can be used as an active compound or bait in $C$. cynocephalus controlling system. The dodecenol existences can be detected through chemical analysis of $\mathrm{BE}$ and SGE using GC-MS (Figure 1). Figure 1 shows that dodecenol peak of $\mathrm{BE}$ arises at retention time 13.05 minutes. This is appropriate to a research showing that 12 carbons compound such as dodecenol has retention time \pm 13.00 minutes [12]. This mentioned that dodecenol peak had risen up at retention time 13.66 minutes, 13.99 minutes, and 13.85 minutes according to its concentration. The chromatogram is then reinforced with mass spectra data showing the presence of dodecenol according to the peak shown in Figure 2.

Figure 2 shows that mass spectra of BE confirmed the existence of dodecenol at retention time 13.05 minutes within its chemical structure

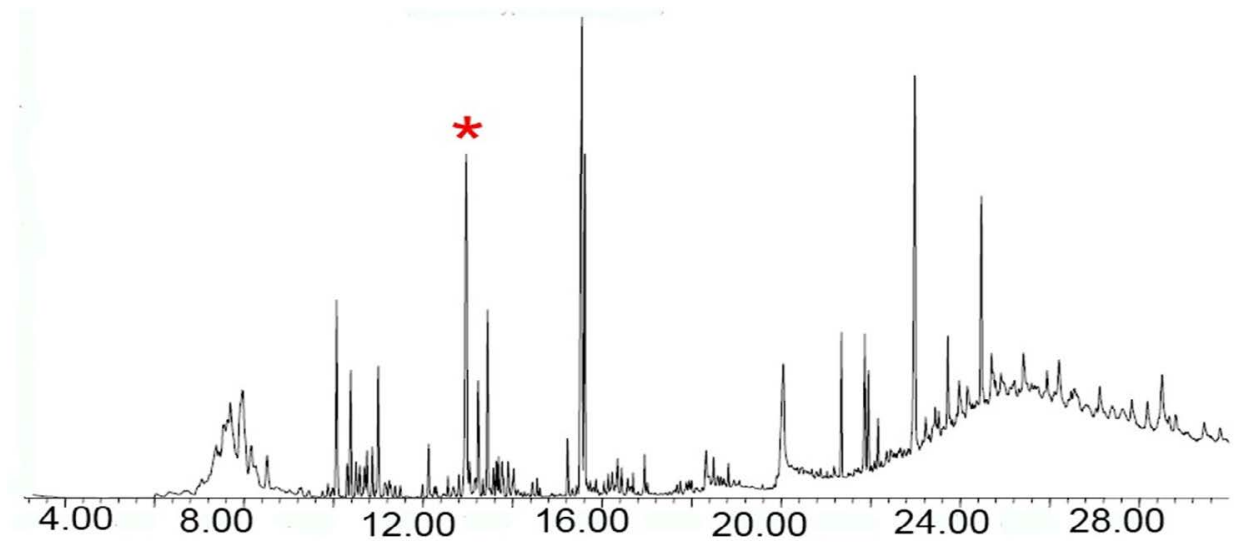

Figure 1: Chromatogram of body extract. 


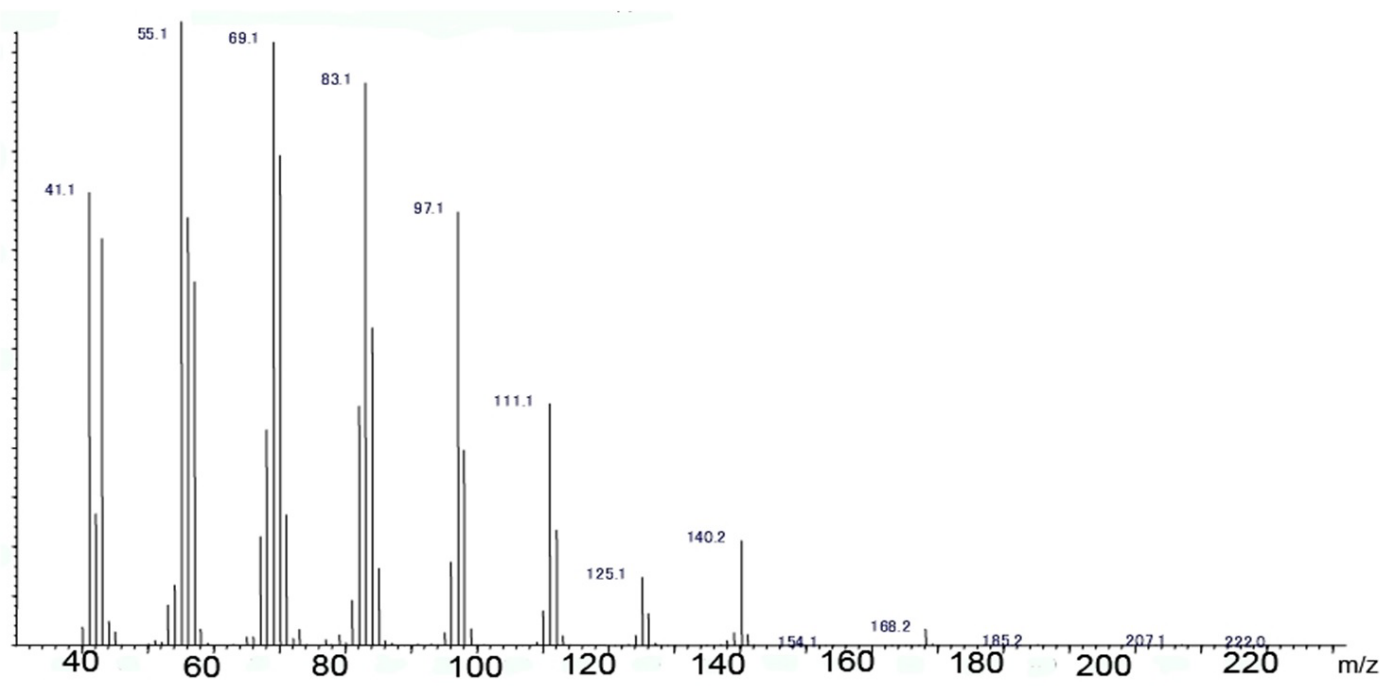

Figure 2: Mass spectra of body extract.

Table 1: Adaptation time and mileage of termites on bioassay $Y$ (mean \pm SD).

\begin{tabular}{|l|l|l|}
\hline Extract & Adaptation time (s) & Distance travelled $(\mathbf{c m})$ \\
\hline BE & $355 \pm 557.80$ & $5.65 \pm 0.52$ \\
\hline SGE & $2858.5 \pm 2563.98$ & $2.15 \pm 0.11$ \\
\hline
\end{tabular}

$\left(\mathrm{C}_{12} \mathrm{H}_{25} \mathrm{OH}\right)$. Based on the structure, dodecenol can be included to long chain alcohol. This is supported by research which stated that dodecenol has 12 carbons and can be called as lauryl alcohol [13]. Lauryl alcohol is one of fatty alcohol compounds such as dodecadienol, trail following pheromone identified on Odontotermes formosanus [8]. Similarly, another study observed nonadecadienone as a pheromone marker on Glossotermes oculatus [14]. The pheromone is generally a complex of long-chain compounds that are highly folatile produced by certain organs.

Commonly, this pheromone is a complex of long chain compound produced by specific organ called sternal gland.

Sternal gland is one of sources producing trail following pheromone in all termites species. This gland is also stated as main sources producing trail following pheromone on worker and pseudergate of dry wood termites [15]. Trail following pheromones found in all termites are commonly grouped to alcohol, aldehyde, and hydrocarbon with molecular weight variations from 180 to 272 [16]. Termite's pheromones are basically same for each termite's family, for example dodecenol as trail following pheromone found in Kalotermitidae includ- ing C. cynocephalus [17].

\section{Bioassay $\mathbf{Y}$}

This study uses two types of extracts namely Body Extract (BE) and Sternal Gland Extract (SGE). Table 1 shows that $B E$ has more influence on termite behavior than SGE. BE affects the termite adaptation time in vial bottles more quickly (355 \pm $557.80 \mathrm{~s})$ than SGE (2858.5 $\pm 2563.98 \mathrm{~s})$. In addition, it is also proved by termites in the BE test that are able to travel a further distance of $5.65 \pm 0.52$ $\mathrm{cm}$ compared to SGE which only affects termites to walk $2.15 \pm 0.11 \mathrm{~cm}$.

This research study show the distance traveled by $C$. cynocephalus movement on SGE bioassay was less than $3 \mathrm{~cm}$ (Table 1). It shown that SGE pheromone is not activated as like as pheromone track of Odontotermes formosanus. Inactivated pheromone caused by the volatile dodecenol that was produced. Alcoholic pheromone such as dedocenol produced by $C$. cynocephalus has high volatility and acting as mimicking nature pheromone from Coptotermes gestroi. At the first 25 minutes the activity of termites were increased, and got down slowly at the next 30 minute [18].

Sternal gland is one of the dodecenol producer in C. cynocephalus. Dodecenol produced by this organ then transported to another organ that physiologically need for regulating somebody mechanisms (eg: Recognizing other worker as trail pheromone). This way that dodecenol concentration in SGE was not affected to termites behavior indicated by short distance traveled. Dodecenol in C. cynocephalus was translocated 


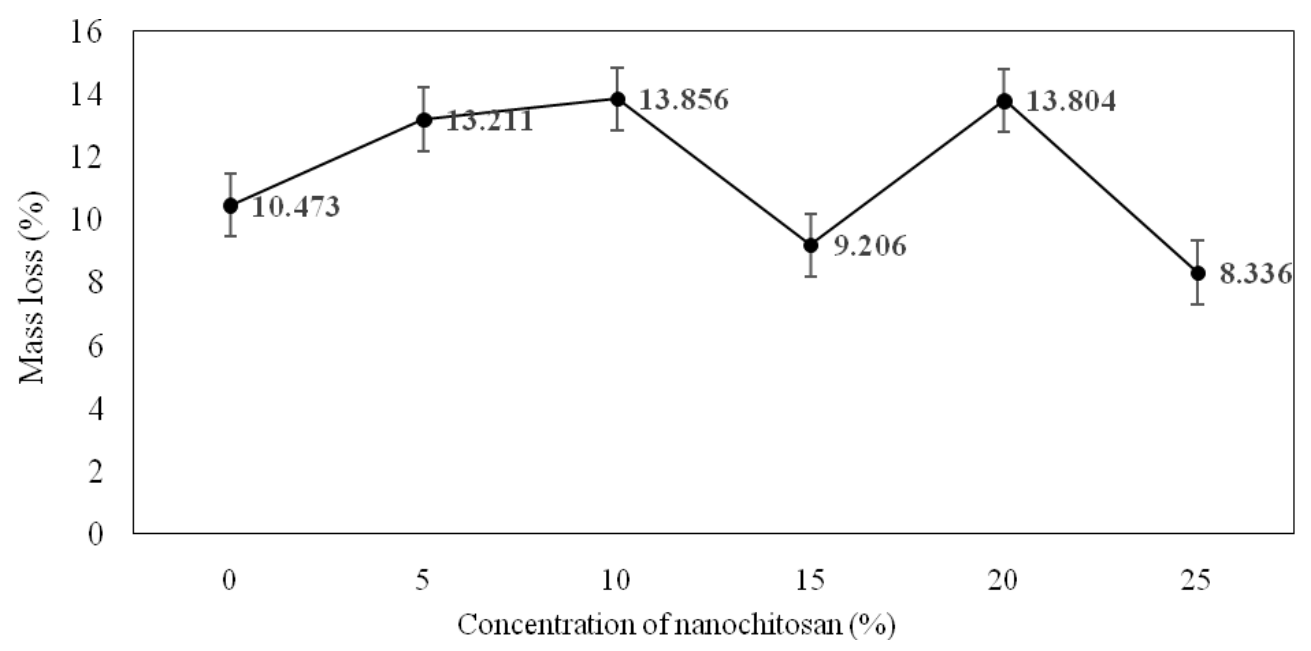

Figure 3: Decreasing of wood mass in the petridis per percent of chitosan concentration.

to antenna on the termite head for recognizing another termite in the colony. So that the dodecenol concentration in the whole body extract was higher than sternal gland extract.

\section{Petridish assay}

$Y$ tube testing was conducted to measure the effect of pheromone in termite preferences of feed wood consuming. Preferences level was indicated by mass loss of feed woods that caused by termite's wood consuming activities. Termite appetite was increased, when given with $0 \%$ to $10 \%$ of nanoparticle and decreased in the $25 \%$ to $30 \%$ of nanoparticle concentration. Maximum wood's mass loss up to $13.86 \%$ in $10 \%$ of nanoparticle group. Then, the wood that submerged in the $20 \%$ of nanoparticle also loss high amount up to $13.80 \%$ but not significantly different. It can be conclude that usage of $10 \%$ nanoparticle is optimum and effective dose in the $C$. cynocephalus control system (Figure 3 ).

\section{Acknowledgment}

Acknowledgment of the authors convey to the Directorate General of Learning and Student Affairs, Ministry of Research, Technology and Higher Education, Indonesia with contract number 547/ B3.1/KM/2017 dated March 09, 2017. Thank you also the author to convey to the Universitas Negeri Semarang in Indonesia and all parties who are willing to assist in this research.

\section{References}

1. Zulyusri, Desyanti, U Mardia (2013) Effectiveness of seed leaves (Sambucus javanica Reinw) as a vegetable insecticide in soil control (Coptotermes sp.). Proc Seminar FMIPA UNILA 521-528.

2. MT Ferreira, RH Scheffrahn (2011) Light attraction and subsequent colonization behaviors of alates and dealates of the West Indian drywood termite (Isoptera: Kalotermitidae). Florida Entomol 94: 131-136.

3. N Subekti, T Yoshimura, F Rokhman, Z Mastur (2015) Potential for subterranean termite attack against five bamboo species in correlation with chemical components. Proc Environ Sci 28: 783-788.

4. A Sumaryanto, SA Hadikusumo, GL Ndaru (2013) J Forestry Sci 7: 93.

5. Y Rismayadi, Arinana (2009) J Sci Technol Forest Product 2: 32.

6. A Rahayu A (2014) Formulasi Tablet dari Nanopartikel Ekstrak Daun Sambiloto (Andrographis paniculata [Burn.f.] Ness) dengan Metode Cetak Langsung, Faculty of Pharmacy, Jakarta, Indonesia.

7. A Peppuy, A Robert, E Semon, C Ginies, M Lettere, et al. (2001) (Z)-dodec-3-en-1-ol, a novel termite trail pheromone identified after solid phase microextraction from Macrotermes annandalei. J Insect Physiol 47: 445-453.

8. P Wen, BZ Ji, DS Dusses (2014) Trail communication regulated by two trail pheromone components in the fungus-growing termite Odontotermes formosanus (Shiraki). PLOS ONE 9: 90906.

9. SW Ali, S Rajendran, M Joshi (2011) Synthesis and characterization of chitosan and silver loaded chitosan nanoparticles for bioactive polyester. Carbohydrate Polym 83: 438-446.

10.L Zhao, L Shi, Z Zhang, J Chen, D Shi, et al. (2011) Preparation and application of chitosan nanoparticles 
and nanofibers. Brazilian J Chem Engineering 28.

11.ME Mankowski, HK Kaya, JK Grace, B Sipes (2005) Differential susceptibility of subterranean termite castes to entomopathogenic nematodes. Biocontrol Sci and Technol 15: 367-377.

12.BOONIE Tay Yen Ping (2013) Gas chromatographyflame ionisation detector method for determination of carbon chain length distribution of palm-based fatty alcohol. J Oil Palm Res 25: 36.

13.VI Babushok, PJ Linstrom, IG Zenkevich (2011) Retention indices for frequently reported compounds of plant essential oils. J Phys Chem Ref Data 40: 1-47.

14.R Hanus, P Zacek, B Kalinova, Šobotník J, Krasulová J, et al. (2012) Nonadecadienone, a new termite trailfollowing pheromone identified in Glossotermes oculatus (Serritermitidae). Chem Senses 37: 55-63.

15.G Bagneres, R Hanus (2015) Communication and social regulation. Springer Int Publ, Switzerland, 193.

16.A Bordereau, JM Pasteels (2011) Biology of termites: A modern synthesis, pheromones and chemical ecology of dispersal and foraging in termites, University of Bourgogne, France.

17.A Sillam-Dusses, A Robert, A Semon, M Lacey, C Bordereau (2006) Trail-following pheromones and phylogeny in termites. Proc of the IUSSI Congress, Washington, DC, USA.

18.A Arab, YC Blanco, AM Costa-Leonardo (2012) Dynamics of foraging and recruitment behavior in the Asian subterranean termite Coptotermes gestroi (Rhinotermitidae). Psyche 1-7. 